\title{
Prevalence, pattern and factors associated with problematic phone use among youths in Kano Metropolis, Nigeria
}

\author{
Taiwo Amole, ${ }^{1,2}$ Omeiza Agoyi, ${ }^{1}$ Fatimah Tsiga-Ahmed ${ }^{1}$ \\ ${ }^{1}$ Department of Community Medicine, Aminu Kano Teaching Hospital Kano/Bayero University Kano; \\ ${ }^{2}$ Africa Center of Excellence for Population Health and Policy Bayero University Kano, Kano, Nigeria
}

\begin{abstract}
Mobile phones have increasingly penetrated our societies with huge benefits accrued from its use. A rapidly growing number of youths are acquiring the cell but the extent to which usage constitutes a problem in their daily lives has not been studied much in northern Nigeria. This study assessed the prevalence, pattern, perceived effect and factors associated with problematic phone use among youths in Kano metropolis. Using a descriptive cross-sectional design, 320 youths aged 15-24 years old who were available on social media sites (Twitter, Facebook and WhatsApp) were studied. A pretested online questionnaire was sent to respondents via the different social media and entries collected for a month. Data was analyzed using SPSS vs 21.0. Majority ( $\mathrm{N}=210 ; 65.6 \%)$ of the study participants were habitual users, while $10.3 \%(n=33)$ were problematic users. An additional $10 \%(n=32)$ were found to be at risk of problematic phone use. Three quarters of the respondents $(n=238 ; 74.4 \%)$ spent five or more hours on their phones per day, more than half $(\mathrm{n}=175 ; 54.7 \%)$ were awakened at least once in the night and majority $(n=230 ; 71.8 \%)$ used their phones in
\end{abstract}

Correspondence: Fatimah Tsiga-Ahmed, Department of Community Medicine, Aminu Kano Teaching Hospital Kano/Bayero University Kano, No 2, Zaria Road, Kano/ PMB 3011 Kano, Kano State, Nigeria. E-mail: fitsiga.cmed@buk.edu.ng

Key words: Problematic phone use, phone addiction, youths.

Conflict of interest: The authors declare no conflict of interest.

Availability of data and materials: All data generated or analyzed during this study are available from the authors upon reasonable request.

Ethics approval and consent to participate: Ethical clearance for the study was obtained from the Research and Ethics Committee of Kano State Ministry of Health (MOH/797/T.I/1292). Prior to filling the survey tool, respondents read the survey information and filled a consent form. Respondents were assured of confidentiality and use of information obtained for the stated purpose(s) only.

Received for publication: 28 January 2021.

Revision received: 9 February 2021.

Accepted for publication: 11 February 2021.

This work is licensed under a Creative Commons Attribution NonCommercial 4.0 License (CC BY-NC 4.0).

CC Copyright: the Author(s),2020

Licensee PAGEPress, Italy

Annals of African Medical Research 2020; 3:142

doi:10.4081/aamr.2020.142 inappropriate situations. Reported symptoms were mainly physical symptoms $(\mathrm{n}=144 ; 45.0 \%)$ such as headache, ear warmth and injuries. Problematic phone use was not associated with sociodemographic factors, however was associated with excessive usage patterns and reported negative symptoms. There is a relatively high prevalence of problematic phone use with reported physical and social consequences among youths in Kano metropolis. Public health strategies that include parents and families would go a long way to limit excessive use of mobile phones among youths.

\section{Introduction}

Young people aged 10 to 24 years have been at the fore of the digital revolution since the late $20^{\text {th }}$ and $21^{\text {st }}$ century with more of them becoming excessively attached to their mobile phones while exhibiting behavioral patterns that appear to be maladaptive. ${ }^{1}$ The portable device is equipped to carry out a range of online and offline activities and has become a social object that is personal, exclusive and intimate. ${ }^{2}$ As such, social interactions among young people are only a button tap. Problematic mobile phone use (PMPU) is currently the most common term used to describe excessive mobile phone use. Other terms found in literature include mobile phone addiction and smartphone addiction. ${ }^{3}$

PMPU is defined as an inability to regulate one's use of the mobile phone, which eventually involves negative consequences in daily life; such as financial problems. ${ }^{4}$ Data from various studies suggests that indeed PMPU is of growing public health concern. ${ }^{5}$ Majority of these studies were conducted among adolescent and young adult populations in Asia, North America, Europe and Australia who bear the direct burden of the technological advancement that has graced people's lives. There is no known universal figure on prevalence of problematic mobile phone use; however, different figures ranging from $5.57 \%$ to $38 \%$ have been reported in adolescents. ${ }^{6}$ This wide range is attributable to disparity in the methodological approach and geographical regions where these studies were conducted. For instance, the national information society agency of South Korea reports a prevalence of $11.4 \%$ among youths, while a recent data from the Pew research estimates that $48 \%$ of smartphone owners indicated that they "couldn't live" without their smartphones. ${ }^{7,8}$

The introduction of mobile phones into Nigeria did not happen until early in the $21^{\text {st }}$ century and its use has increasingly become widespread and pervasive over the years, so much so that for many, it is impossible to imagine life without their mobile phones. ${ }^{9}$ Undeniably mobile phone use comes with numerous advantages, but it has also brought about adverse effects in the realms of psychological wellbeing, interpersonal relationships, and physical health. ${ }^{10}$ Problematic mobile phone use looks set to become one of the biggest behavioral addictions of the $21^{\text {st }}$ century owing to the increasing penetration of mobile phones, their evolution and the general acceptance of this technology particularly by adolescents 
and young adults, but not excluding the older generations. Despite the growing concern of problematic phone use by public health experts and the general public at large, there isn't nearly sufficient research work conducted on in this setting and this study set to determine the prevalence, pattern, reported effects and factors associated with problematic phone use among youths in Kano metropolis, Nigeria.

\section{Materials and Methods}

The study was conducted in Kano state, located in the northwest geo-political zone of Nigeria. Kano state is the most populous state in Nigeria, with a 2016 projected population of $13,076,892$ (with about three-quarter of this population being under the age of 30). ${ }^{11,12}$ Eight local government areas (Fagge, Gwale, Tarauni, Kano Municipal, Nassarawa, Dala Kumbotso and Ungogo) constitute the metropolis.

The total number of active voice and internet subscriptions on mobile devices (GSM) in Kano state was estimated to be $9,715,934$ and $5,829,912$ respectively at the end of the $4^{\text {th }}$ quarter of 2018. Kano has the $3^{\text {rd }}$ highest number of subscriptions in the country. ${ }^{13}$

\section{Study design}

This study was a descriptive cross-sectional study conducted between May and August 2019.

\section{Study population}

The study population consisted of youths (aged 15-24 years) available on online social media sites residing within Kano metropolis. Youths who had owned a smartphone device for at least 1 year and had internet access were eligible while those whose occupation directly involved prolonged phone use, worked at telecommunication call centres or were social media influencers were excluded.

\section{Sample size calculation}

The minimum sample size for the study was determined using formula for estimating minimum sample size for health studies with one study group and qualitative outcomes: $n=Z^{2} \mathrm{pq} / \mathrm{d}^{2} ; \mathrm{p}$ $(=21.3 \%)$ was the prevalence of problematic phone use from a previous study ${ }^{14}$ and a precision of 0.05 . The calculated sample size $(=258)$ was increased by $37 \%$ to adjust for non-response, ${ }^{15}$ to arrive at a final sample size of 354 participants recruited for this study.

\section{Sampling technique}

To recruit a diversity of youth in Kano metropolis, an online survey was done. A newsletter inviting prospective respondents who met the eligibility criteria to participate in the study was made available on three major online social media sites (Twitter, Facebook and WhatsApp). Every $3^{\text {rd }}$ eligible respondent was selected and sent a link that had the study information, consent form and a link to the questionnaire. The study information form explained the nature of the research and emphasized the confidentiality of their responses. The selection process was opened until 354 participants were recruited. The first participant was selected by simple random sampling (by balloting). This process is referred to as intercept surveys, a random sampling method peculiar to web-based online surveys. ${ }^{16}$

\section{Data collection and management}

Data was collected using a pretested self-administered online questionnaire (Google forms) adapted from previous studies. ${ }^{17-19}$ The questionnaire consisted of four sections. The first section was on the socio-demographic details of participants. The second section focused on determining the prevalence of problematic phone use using the Mobile Phone Problem Use Scale - Short Version (MPPUS-10) consisting of ten questions measured on a 10-point likert scale. The questions included: "I use my phone to make myself feel comfortable", "when out of range for some time, I become preoccupied with the thought of missing a call or text", "If I don't have a phone, my friends would find it hard to get in touch", "I feel anxious if I have not checked for messages or switched on my mobile phone for some time", "my friends and family complain about my use of the mobile phone", "I find myself engaged on the mobile phone for longer periods of time than intended", "I am often late for appointments because I'm engaged on my mobile phone when I shouldn't be", "I find it difficult to switch off my mobile phone", "I encounter difficulties paying my mobile phone bill". The third section identified the pattern of phone use and the last section assessed the reported effects (physical, social, psychological and financial problems) of phone use among participants. Clear instructions in the simplest possible language were provided for filling the questionnaire. Respondents could edit incomplete/inappropriate responses.

Generated data were automatically entered into Google spreadsheet, transferred to Microsoft Excel for data cleaning and analyzed using SPSS version 21.0. Qualitative data were expressed in simple frequencies and percentages while quantitative data were expressed using mean and standard deviation or median and range as appropriate. For the MPPUS, the possible score for the ten questions ranged from 10 to 100 . Using the $15^{\text {th }}, 80^{\text {th }}$ and $90^{\text {th }}$ percentiles for pattern of users of the MPPUS- $10 ;{ }^{5}$ corresponding participants' scores of 36, 71 and 78 were marked as cut-offs and categorized as Occasional Users, Habitual Users, At Risk Users and Problematic Users. Questions were asked on what respondents had experienced in the domains of physical, financial, social and psychological effects of phone use. Respondents with one or more effect/symptom in each domain were grouped as 'yes' while those without any effect in the domain were grouped as 'no'. For the tests of association, phone use was the outcome variable and dichotomized such that other patterns of phone use were one group and PMPU was the second group. At bivariate analysis, the Chi Sq test was used to determine factors associated with PMPU. Problematic phone use was the outcome/dependent variable and its predictors were determined using a backward selection regression model. The independent variables included variables that had pvalue $<0.1$ at bivariate analysis. Gender and education were included in the model as a priori confounding variable. A p-value of $\leq 0.05$ was considered as statistically significant.

\section{Ethical considerations}

Ethical clearance for the study was obtained from the Research and Ethics Committee of Kano State Ministry of Health (MOH/797/T.I/1292). Prior to filling the survey tool, respondents read the survey information and filled a consent form. Respondents were assured of confidentiality and use of information obtained for the stated purpose(s) only. 


\section{Results}

All 354 responses were screened and 320 were found to be complete and included in the analysis. The ages of respondents ranged from 16 to 24 years with a mean age of $21.1 \pm 2.2$ years. Most $(n=230 ; 71.9 \%)$ of them were young adults aged $20-24$ years, Muslims $(\mathrm{n}=297 ; 92.8 \%)$ and Hausa/ Fulani $(\mathrm{n}=236$; $73.8 \%$ ); other tribes constituted $26.2 \%$. Majority of them $(n=261$; $81.9 \%)$ were still in school of which most $(n=246 ; 94.3 \%)$ were currently in tertiary institutions (Table 1).

\section{Prevalence and pattern of use}

Respondents' scores on the MPPUS ranged from 10 to 97. The question "If I don't have a phone, my friends would find it hard to get in touch" had the highest mean score $(7.89 \pm 2.46)$ and "I am often late for appointments because I'm engaged on my mobile phone when I shouldn't be" had the lowest mean score (3.19 \pm $2.7)$. The majority $(n=210 ; 65.6 \%)$ were habitual users, while $10.3 \%(\mathrm{n}=33)$ were problematic users (Table 2$)$.

Respondents' age of owning first mobile phone ranged from 4 to 20 years with a mean age of $13.8 \pm 3.2$ years. The majority $(\mathrm{n}=193 ; 60.3 \%)$ had one phone and made $0-40$ calls per day with a median of 5.00 and IQR of 7 calls. The average amount of time spent on the mobile phone daily was estimated to be between 1-18 hours with a median 8 and IQR range of 6 hours. More than half $(\mathrm{n}=175 ; 54.7 \%)$ were awakened at least once during the night and about a third ( $\mathrm{n}=99 ; 30.9 \%)$ were always/frequently involved in inappropriate use (Table 3).

\section{Reported effects}

Physical symptoms $(n=144 ; 45.0 \%)$ such as headaches, ear warmth and injuries were the commonest reported effects of mobile phone use. This was closely followed by psychological

Table 1. Socio-demographic characteristics of respondents.

\begin{tabular}{lcc}
$\begin{array}{l}\text { Socio-demographic } \\
\text { characteristic }\end{array}$ & $\begin{array}{c}\text { Frequency } \\
\text { (n) }\end{array}$ & $\begin{array}{c}\text { Percentage } \\
(\%)\end{array}$ \\
Age Group (years) & & 28.1 \\
$\quad$ Teenagers (15-19) & 90 & 71.9 \\
$\quad$ Young adults (20-24) & 230 & \\
Gender & & 50.0 \\
$\quad$ Male & 160 & 50.0 \\
$\quad$ Female & 160 & \\
\hline Ethnicity & & 73.8 \\
$\quad$ Hausa/Fulani & 236 & 26.3 \\
$\quad$ Others & 84 & 7.2 \\
Religion & & 92.8 \\
$\quad$ Christianity & 23 & \\
$\quad$ Islam & 297 & 81.9 \\
Schooling status & & 16.1 \\
$\quad$ In-school & 261 & \\
$\quad$ Out-of-school & 59 & 5.7 \\
Current level of education (n=261) & & 94.3 \\
$\quad$ Secondary & 15 & 67.2 \\
Tertiary & 246 & 20.0 \\
\hline Employment status & & 12.8 \\
$\quad$ Unemployed & 215 & \\
Self employed & 64 & Employed \\
\hline
\end{tabular}

*Others include; Kanuri, Nupe, Idoma, Edo, Gizim, Arab, Gbagyi and Urhobo. $(\mathrm{n}=126 ; 39.4 \%)$ and social $(\mathrm{n}=125 ; 39.1 \%)$ symptoms. In the psychological domain, poor concentration $(n=81 ; 64.3 \%)$ and sleep disturbances $(76 ; 60.3 \%)$ were the commonest while the most reported social problem was inability to complete tasks when due $(\mathrm{n}=103 ; 82.4 \%)$.

\section{Factors associated with PMPU}

Respondents' socio-demographic characteristics were not significantly associated with PMPU. The pattern of use and reported effects of phone use were however significantly associated with PMPU. Respondents with 2 or more phones ( $\mathrm{n}=20 ; 16.0 \%)$ experienced PMPU more than their counterparts with 1 phone $(n=13$; $6.7 \%)\left(\chi^{2}=7.17 ; p=0.007\right)$. Those who spent ten and more hours per day on the phone also experienced PMPU more than those who spent less time on the phone $\left(\chi^{2}=25.43 ; p=0.0001\right)$. PMPU was also significantly associated with the report of physical $\left(\chi^{2}=11.43\right.$; $p=0.001)$, social $\left(\chi^{2}=17.52 ; 9=0.0001\right)$ and financial $\left(\chi^{2}=4.32\right.$; $9=0.04$ ) symptoms (Table 4$)$. After adjusting for confounders, respondents who spent ten or more hours per day on the phone were more than seven times $(\mathrm{aOR}=7.12,95 \% \mathrm{CI}$ [1.96- 5.93])

Table 2. Prevalence of problematic phone use using MPPUS scores.

\begin{tabular}{lccc}
$\begin{array}{l}\text { Type of } \\
\text { phone users }\end{array}$ & $\begin{array}{c}\text { MPPUS } \\
\text { Score }\end{array}$ & $\begin{array}{c}\text { Frequency } \\
\text { (n) }\end{array}$ & $\begin{array}{c}\text { Percentage } \\
(\%)\end{array}$ \\
Occasional users & $\leq 35$ & 45 & 14.1 \\
Habitual users & $36-70$ & 210 & 65.6 \\
\hline At Risk users & $71-77$ & 32 & 10.0 \\
Problematic users & $\geq 78$ & 33 & 10.3 \\
\hline
\end{tabular}

Table 3. Pattern of phone use among respondents.

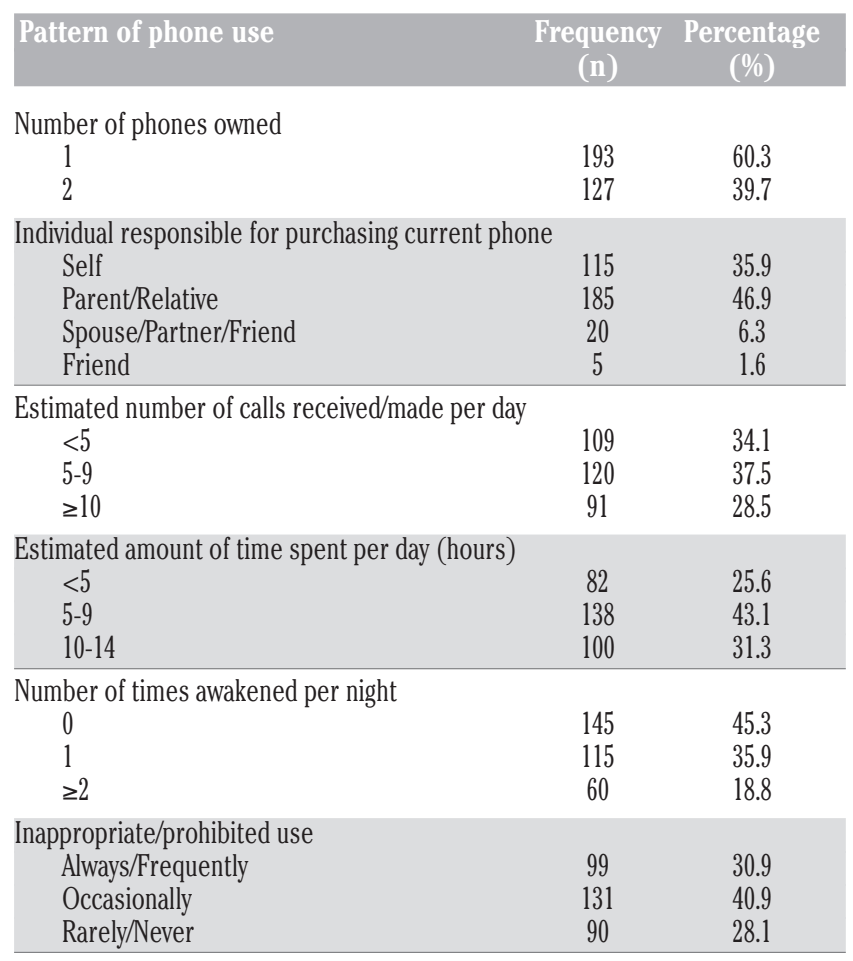


more likely to experience PMPU than their counterparts who spent less than 10 hours. Also, those who had two or more phones were thrice $(\mathrm{aOR}=3.00,95 \% \mathrm{CI}[1.32-6.82])$ more likely to experience PMPU. Respondents who did not report physical symptoms and social problems were $61 \%(\mathrm{aOR}=0.39,95 \% \mathrm{CI}[0.16-0.94])$ and $72 \%$ less likely $(\mathrm{aOR}=0.28,95 \% \mathrm{CI}[0.12-0.67])$ respectively to experience PMPU (Table 5).

\section{Discussion}

This study noted 1 in 10 youths encounters the negative influence of phone use in their daily lives. Our finding constitutes a significant proportion as it implies that of Nigeria's youthful population (15-24 years), about 3.64 million individuals are experiencing these negative effects. ${ }^{20}$ When both at risk and problematic users are combined, this picture worsens with about 1 in 5 youths categorized as 'users with problem'. More so, this figure may rise in the near future considering the increasing penetration of smartphones in Nigeria. These findings are similar to what was reported among British $(10 \%)^{6}$ and Spanish youths (10.4\%). ${ }^{21}$ However, the prevalence obtained from this study was found to be much higher than those obtained from studies using the MPPUS tool when applied to the general population. ${ }^{14,22}$ This signifies that the prevalence of problematic phone use is higher among younger individuals. The differing prevalences may be from the diversity of instruments and classification criteria used in the different studies; thus making comparability of findings difficult. ${ }^{6}$

The pattern of phone used observed in this study may be a pointer towards the development of PMPU. About a quarter of the youths spent more than five hours per day and received more than five calls per day. This will translate to incurring expenses on airtime and data usage. Despite the apparent economic hardship in the country, youths are still likely to raise money to cater for their phone expenses regardless of the cost - a pattern which is commonly observed in other addictions such as alcoholism, substance abuse and gambling. ${ }^{23}$ About a quarter of respondents admitted experiencing financial hardship linked to their phone use. Also, more than half of respondents $(54.7 \%)$ were awakened at night on an average, with 18.8 percent of respondents waking up twice or

Table 4. Factors associated with problematic phone use.

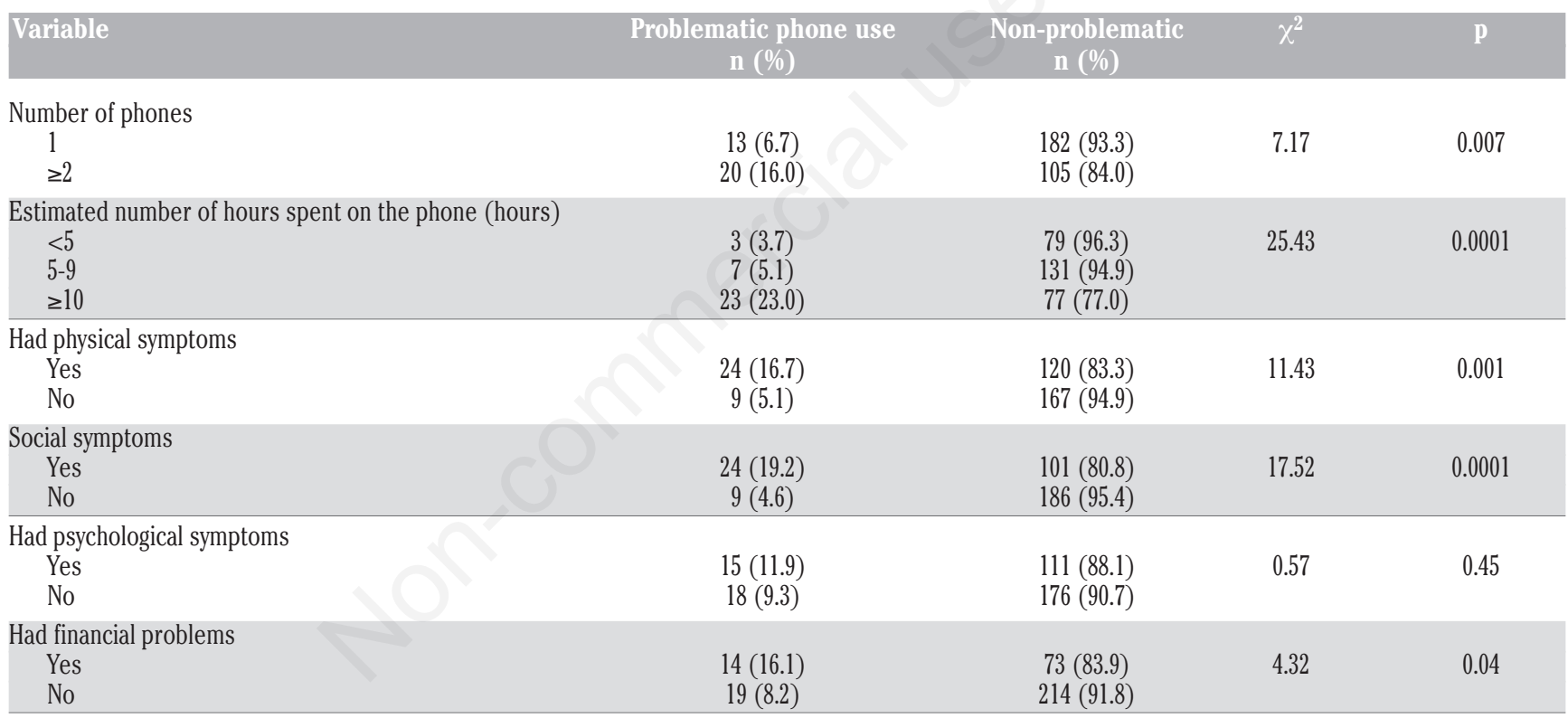

Table 5. Predictors of PMPU.

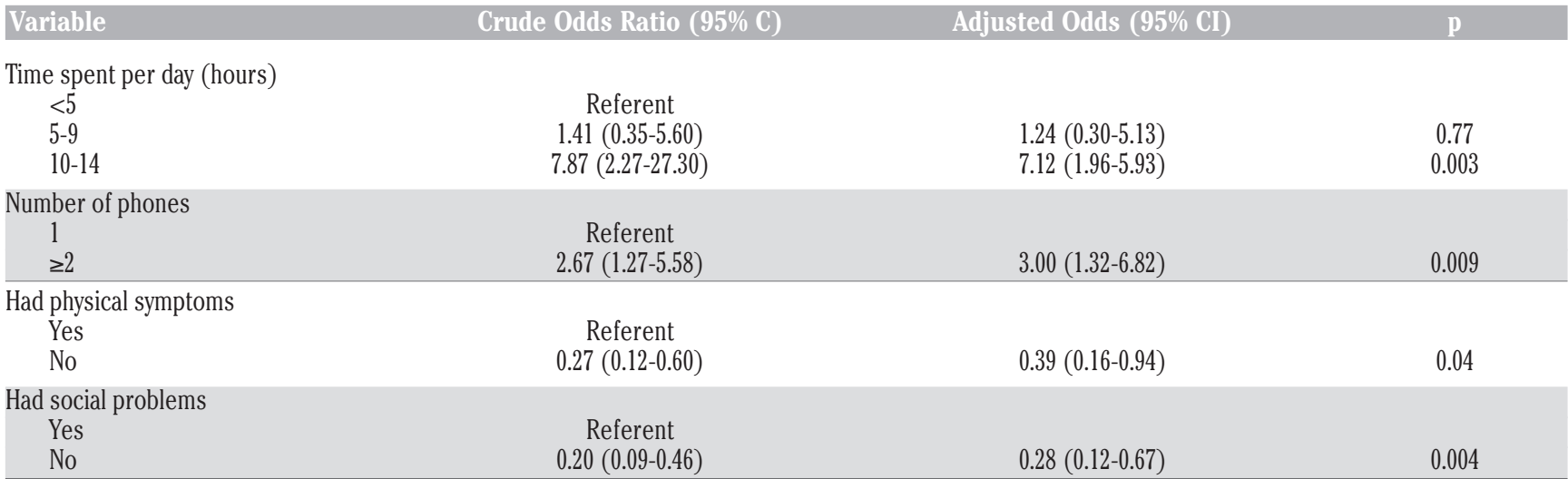


more per night, which may impair their quality of sleep and productivity. Studies have shown that sleep disturbances and poor sleep quality have negative impact on general health and feeling of well-being along with impaired cognitive function and poor academic performance. ${ }^{24}$

The frequency of mobile phone use in situations that are inappropriate such as in class, libraries, banks, gas stations, while driving, etc., is also common as about a third of the respondents admitted to using their phones either 'always/frequently' in such circumstances. Phones are banned in many public places because they may inhibit the user from being able to focus and/or function properly in social gatherings or may even constitute potential hazards. A similar study reported that $71 \%$ of the students studied used their phones in public places. ${ }^{17}$

Phone use also affects the health of these youths. Almost half (45\%) admitted to having experienced physical symptoms associated with their mobile phones in the last 1 year. Headaches, musculoskeletal pain affecting the hands, wrists, neck; blurriness of vision, tearing, painful eyes were common. A significant proportion $(40 \%)$ of them reported an array of social problems that they attributed to phone use. The most frequently experienced was "inability to complete tasks at the right time" and this may highlight the distracting influence phones may pose. Some $(15 \%)$ of them admitted that phone use affected their grades negatively in the past. The respondents also reported other negative effects such as poor concentration, sleep disturbances and anxiety symptoms; which may all impact negatively on academic performance. Theoretically, mobile phones are supposed to foster kinship ties by bridging the gap in distance. High user adolescents and young adults find themselves isolated from the family set up, ${ }^{19}$ and a few in this study (13.1\%) admitted having felt isolated from family and friends in the last 1 year.

About one-third of respondents admitted to being distracted by their mobile phones. This carries huge implications because, activities such as driving requires full concentration and operating a mobile phone while driving increases the chances of having an auto crash. Not surprisingly, about $18 \%$ of those who drive had experienced an accident within the last year related to their phone use.

Patterns indicating excessive mobile phone use (time spent on the mobile phone, number of phones owned) and having experienced negative consequences (physical symptoms, social problems and financial hardship) all had significant associations with PMPU. Increasing number of phones tend to increase time spent on phones and this in turn may predispose to experiencing health complications. Researches have documented the negative impact of mobile phones on the mental, physical and social health of its users, especially younger adolescents and adults. ${ }^{23,25}$

This study has its limitations. We assessed the presence of symptoms associated with respondents' use of the mobile phone and did not quantify by evaluating its duration or frequency. Also, the study required a degree of internet literacy among the participants and less conversant users may have opted out of the study. Thus, the results may not be a true representation of the general population owing to the peculiarities of individuals who have access to online social media sites. It however gave insightful information on the magnitude of PMPU among the youth in our setting.

\section{Conclusions}

Problematic Mobile Phone Use is common among youths in Kano and can be associated with negative health and social conse- quences especially among youths that have many phones and spend long hours on them. Parents, teachers and other stakeholders in education and training would need to be aware of the implication of this menace so collaborative efforts can be implemented to control the epidemic of phone use addiction. Future research to determine the risk factors for mobile phone addiction would also shed more light on addressing the menace.

\section{References}

1. Ahmed I, Qazi TF, Perji KA. Mobile phone to youngsters: Necessity or addiction. Afr Jo Bus Manag 2011;5:12512-19.

2. Carbonell X, Oberst U, Beranuy M. The cell phone in the twenty-first century: a risk for addiction or a necessary tool? In: Principles of addiction. San Diego: Elsevier Inc.; 2013: p. 901-9

3. Meagher B. Problematic mobile phone use: An emerging disorder? Psych 2017;39. Available from: https://www.psychology.org.au/for-members/publications/inpsych/ 2017/oct/Problematic-mobile-phone-use-An-emerging-disorder

4. Billieux J. Problematic use of the mobile phone: a literature review and a pathways model. Current Psychiatry Reviews 2012;8:1-9.

5. Van Velthoven MH, Powell J, Powell G. Problematic smartphone use: Digital approaches to an emerging public health problem. Digit Heal 2018;4:1-9.

6. Lopez-Fernandez O, Honrubia-Serrano L, Freixa-Blanxart M, Gibson W. Prevalence of Problematic Mobile Phone Use in British Adolescents. Cyberpsychol Behav Soc Netw 2014;17:91-8.

7. Elhai JD, Dvorak RD, Levine JC, Hall BJ. Problematic smartphone use: A conceptual overview and systematic review of relations with anxiety and depression psychopathology. J Affect Disord 2017;207:251-9.

8. National Information Society Agency. Report on the Development of Korean Smartphone Addiction Proneness Scale for Youth and Adults. Seoul: The Agency; 2011

9. Stephen N. History of Global Systems for Mobile Communication in Nigeria. Available from: https://onlinenaijatech.blogspot.com/2012/06/history-of-global-system-formobile.html

10. Kim D, Lee Y, Lee J, et al. Development of Korean Smartphone Addiction Proneness Scale for Youth. PLoS One 2014;9:e97920.

11. National Bureau of Statistics, National Population Commission. National Population Estimates. 2016.

12. Brinkhoff T. Kano. Available from: https://www.citypopulation.de/php/nigeria-admin.php?adm1id=NGA020

13. National Bureau of Statistics. Telecoms Data: Active Voice and Internet per State, Porting and Tariff Information. 2019.

14. De-Sola J, Talledo H, Rodríguez de Fonseca F, Rubio G. Prevalence of problematic cell phone use in an adult population in Spain as assessed by the Mobile Phone Problem Use Scale (MPPUS). PLoS One 2017;1-17.

15. Atif A, Richards D, Bilgin A. Estimating non-response bias in a web-based survey of technology acceptance: a case study of unit guide information systems. 23rd Australasian Conference on Information Systems. 2012. Available from: https://www.researchgate.net/publication/280860298_Estimati $\mathrm{ng} \mathrm{g}_{-} \mathrm{N}$ - R e s p ons e $\mathrm{B}_{\mathrm{i}} \mathrm{as} \mathrm{s}_{-} \mathrm{in} \mathrm{a}_{-} \mathrm{W}$ e b Based_Survey_of_Technology_Acceptance_A_Case_Study_o 
f_Unit_Guide_Information_Systems/link/57ad257a08ae7a642 0c35225/download

16. Fricker RD. Sampling Methods for Web and E-mail Surveys. In: The SAGE Handbook of Online Research Methods. 2 ed. SAGE Publications Limited; 2016: p. 195-216.

17. Gupta N, Garg S, Arora K. Pattern of mobile phone usage and its effects on psychological health, sleep, and academic performance in students of a medical university. Natl J Physiol Pharm Pharmacol 2016;6:132-9.

18. Söderqvist F, Carlberg M, Hardell L. Use of wireless telephones and self-reported health symptoms: A population-based study among Swedish adolescents aged 15-19 years. Environ Heal 2008;7:1-10.

19. Foerster M, Roser K, Schoeni A, Röösli M. Problematic mobile phone use in adolescents: derivation of a short scale MPPUS-10. Int J Public Health 2015;60:277-86.

20. United Nations Population Fund. Adolescents and Youth Dashboard - Nigeria. 2017. Available from:
https://www.unfpa.org/data/adolescent-youth/NG

21. Jenaro C, Flores N, Gomez-Vela M, Gonzalez-Gil F, Caballo C. Problematic Internet and cell-phone use: psychological, behavioral and health correlates. Addict Res Theory 2007;15:309-20.

22. Smetaniuk P. A preliminary investigation into the prevalence and prediction of problematic cell phone use. J Behav Addict 2014;3:41-53.

23. Kuss DJ, Kanjo E, Crook-Rumsey M. et al. Problematic mobile phone use and addiction across generations: the roles of psychopathological symptoms and smartphone use. J Technol Behav Sci 2018;3:141-9.

24. Brown FC, Buboltz WC, Soper B. Relationship of sleep hygiene awareness, sleep hygiene practices, and sleep quality in university students. Behav Med 2002;28:33-8.

25. Billieux J. Problematic use of the mobile phone: a literature review and a pathways model. Current Psychiatry Reviews 2012;8:299-07. 